\title{
ENSINO CENTRADO NO ESTUDANTE: RELATO DE EXPERIÊNCIA DE ALUNAS NESTA METODOLOGIA*.
}

\author{
Edelia del Pilar Neira Huerta** \\ Lélia Maria Madeira** \\ Maria Teresa Cicero Lagciná** \\ Matilde Meire Miranda**
}

NEIRA HUERTA, E. del P.; MADEIRA, L. M.; LAGANA, M. T. C.; MIRANDA, M. M. Ensino centrado no estudante: relato de experiência de alunas nesta metodologia. Rev. Esc. Enf. USP, São Paulo, 18(2):141-149, 1984.

Quatro mestrandas em enfermagem relatam sua experiência como alunas de uma disciplina que adota a metodologia de ensino centrado no estudante. Mostram suas dúvidas iniciais em relaçâo à efetividade da metodologia, as dificuldades sentidas na formulaf̧āo de um programa e sua percep̧ão da atitude e do comportamento apresentados pelo professor-facilitador. Para atingir seus objetivos de aprendizado, o grupo optou por uma experiência de assistência materno-infantil numa favela de São Paulo. O trabalho foi implantado com as mäes e outros adultos responsáveis pelo cuidado de crianças, utilizando-se a comunicação não-diretiva. Apesar da metodologia nāo tradicional, neste trabalho é possivel identificar os diferentes elementos necessários a um curso. As autoras ressaltam, como principais efeitos do processo por elas vivido, o desenvolvimento profissional, tanto individual como de grupo, no desenvolvimento de cada uma como pessoa.

\section{INTRODUÇÃO}

Por ocasião da inscrição ao curso de mestrado, cada uma de nós foi entrevistada pela futura professora da disciplina Enfermagem Pediátrica II disciplina da área de concentração - que seria oferecida apenas no segundo semestre do curso. Na entrevista respondemos à pergunta: "O que você espera do mestrado?". As respostas foram consideradas como o primeiro levantamento de nossas necessidades e expectativas, realizado por nossa professora. Não sabíamos, mas era o início da formulação de um programa para essa disciplina e, como foi utilizada a entrevista não-diretiva, sabemos agora que também foi o início da compreensão de nós mesmas.

- Trabalho apresentado à disciplina "Problemas do Ensino de Enfermagem" do Curso de Pós-Graduação (EEUSP), 1983.

* Mestrandas de Enfermagem Pediátrica da Escola de Enfermagem da Universidade de Sáo Paulo (EEUSP), 1983. 
Antes de iniciarmos a disciplina a professora fez nova entrevista conosco, porém em grupo. Cada uma de nós colocou suas expectativas em relação à mesma. Nós tinhamos mudado em conseqüência de experiências vividas em disciplinas do primeiro semestre, algumas individualmente, outras em grupo, consideradas significativas.

Tínhamos muitas necessidades individuais que abrangiam os seguintes aspectos: o conhecimento da criança; a interação com a criança, os pais, as enfermeiras, os alunos e a sociedade; estávamos também preocupadas em melhorar nossa pessoa e em aceitar as diferentes pessoas.

No começo dos encontros de Enfermagem Pediátrica II, a orientadora nos entregou um programa avisando-nos que ele era deficiente, pois acreditava que um programa deveria atender às necessidades dos alunos e não basear-se naquilo que o professor acredita ser importante para o desenvolvimento e aprendizado dos mesmos. A vontade de aceitar aquele programa foi grande, mas, já sabíamos que ele năo atenderia às nosssas necessidades já identificadas.

Era necessário formular objetivos para o nosso programa. O processo de conciliar interesses e necessidades foi lento e difícil. Talvez nunca o tivéssemos conseguido sem a ajuda da professora. Ela foi, continuamente, um catalizador, emprezando técnicas que somente agora comos capazes de reconhecer e identificar, levando-nos constantemente a percepçăo de nós mesmas.

- O que pensávamos?

- O que sentíamos?

- O que queríamos aprender?

- O que seria bom para cada uma de nós?

Cada uma com o auxílio da professora, anslisava o que percebia acontecer dentro de si a cada novo encontro - sentimentos, emoçð̌es, vontades -. Foram os encontros mais cansativos que já tivemos; a responsabilidade de pensarmos sobre tudo pesava muito.

Continuando os encontros semanäis descobrimos, também, que havia centros de interesse comuns entre nós e que, portanto, seria interessante trabalharmos juntas neles; partindo disto fariamos nossa programação para suprir necessidades individuais.

Baseando-nos em nossas necessidades comuns, conseguimos formular um objetivo geral para nosso curso, que seria:

- "construir uma base para ser um bom profes.sor, um bom pesquisador e um bom enfermeiro, considerando as necessidiades da população, as ten- 
dências atuais do ensino aprendizagem e da assistência de enfermagem, visando, principalmente, a formação em saúde da populaçăo assistida e considerando a organização social de uma comunidade."

Como atingiríamos este objetivo?

Seria necessário, em primeiro lugar, definir a população, conhecer sua organização e suas necessidades prioritárias. Em seguida, identificar $e$ analisar os recursos assistenciais disponíveis; depois, tentar viver um papel onde pudéssemos capacitar os responsáveis pelas crianças a conhecer e atender suas necessidades.

Para atender a este objetivo, nossa professora nos ofereceu três locais onde pudéssemos viver a experiência e providenciou os recursos para entrarmos em contato com estes locais.

Optamos pelo trabalho numa favela pelas razóes abaixo referidas.

- Já existia uma estrutura organizada de trabalho: uma escolinha, três creches com lactentes e pré-escolares, assistidas por máes da própria favela, e um ambulatório para atendimento geral, com um atendente de enfermagem e três médicos, que atendiam em tempo parcial e alternadamente. Todos estes recursos funcionavam sob a orientação de um grupo de voluntários alemaes, que por mais de seis anos vem implantando atividades com as crianças e adolescentes nesta favela. A existência desta estrutura facilitaria nossos contatos, considerando-se o fator tempo.

- Teríamos exatamente a experiência que queríamos, que era conviver com a população carente no seu meio ambiente, com suas características sócio-economico-políticas e culturais peculiares.

A forma de abordá-las, para possibilitar o trabalho, determinaria um novo aspecto na formação da enfermeira pediátrica;

- A filosofia de trabalho das professoras voluntárias baseava-se na crença de que só o trabalho com crianças valia a pena; esta crença relacionava-se ao fato das crianças serem mais susceptíveis que os adultos para receberem alguma formação; acreditavam que, naquele meio social tão hostil no qual vivem as crianças, algumas horas passadas na escolinha, recebendo os efeitos da pedagogia que empregam (Pedagogia Waldorf), minimizaría as penúrias de seu mundo real e, de certa forma, diminuiria a oportunidade de se tornarem delinqüentes juvenis e futuros marginais. Acreditavam também que, com os adultos, jâ não havia mais possibilidades, pois haviam tentado reunioes com os pais e nada tinham conseguido; concluiram que os adultos já tinham sua personalidade formada $e$, portanto, era práticamente impossível modificá-los.

Isto constituiu para nós um grande desafio, por considerarmos que a enfermagem pediátrica se faz através das pessoas que cuidam da criança; assim, 
Por intermédio de uma professora interessada na educação de adultos, que já era um elemento conhecido na comunidade, estabeleceríamos o elo de ligação entre nós e as mães; e por meio de encontros, nos quais seria utilizadá a técnica de comunicação năo-diretiva tentaríamos capacitar as professoras a lidarem com as mães e as mães a lidarem com seus filhos. Queriamos mostrar que o adulto, também é capaz de aprender, desde que saibamos como abordá-lo.

Partindo desse princípio, decidimos visitar a favela para conhecermos o ambiente, as condiçठes de vida e os recursos existentes. Entrainos em contato com as professoras da escolinha e com pessoas do ambulatório, o aniciente, as condiçōes de vida e os recursos existentes, entramos em contato com as professoras da escolinha e com as pessoas do ambulatório, conhecemos alquns voluntários e visitamos algumas famílias. Descobrimos que entre as professoras. as voluntárias e o atendente do ambulatório já havia expectativa em relação ao nosso trabalho ali. Este incluia palestras sobre cuidados ao recém-nascido e lactente, imunizaçōes e alimentação infantil: atendimento a algumas fam ias para seguimento de tratamento mé dico: ajuda no atendimento ambulaturial e até a organização de estantes de medicamentos.

Nesta ocasia conversamos com a coordenadora das atividades da favela e the expusemos nosso interesse em trabalhar com os responsáveis pelas crianças, a fim de ajudá-los a descobrir suas necessidades e seus problemas em relação a si mesmos e às crianças. Explicamos que estávamos buscando outro papel para o enferm.iro: o de catalizador que levasse os favelados a enfrentarem e modificarem as condições que geram situações de vida desfavoráveis ao seu bem-estar.

Teriamos choque entre as expectativas das voluntárias e as nossas e estavamos ansiosas quanto ac que realmente conseguiriamos fazer naquela comunidade. Esta nossa ansiedade fez com que nossa professora nos ajudis se a expressar nossos sentimentos através de perguntas.

- Como você se vê neste curso e porque?

- Como vocé pensa que deveria ser organizada a experiência na favela?

- O que aconteceu com vocé por ocasiâo do último dia na favela?

- O que voce gostaria de fazer para seu desenvolvimento?

Isto serviu para que pudéssemos refletir sobre as açôes a desempenhar na favela, uma vez que, naquele momento, predominavam nossas emoçðes.

Após respondermos às perguntas e reavaluarmos nossa atuação até então, sentimos que era necessáric estabelecer uma filosofia de trabalho, uma meta a ser aicançada e os objetivos das reunioes com as mães, para que pudéssemos determinar melhor nossns niveis de a tuacâo. Foj o que fizemos 
- Filosofia:

"Cada ser humano é potencialmente capaz de identificar suas necessidades e seus problemas, sentindo, pensando e agindo para resolvê-los."

- Meta:

"Sensibilizar o grupo de pais e professores para que juntos sintam-se ca pazes de identificar problemas e necessidades, trabalhando em conjunto para solucioná-los."

- Objetivos das reuniōes:

- iniciar e manter um tipo de relacionamento em grupo, em que haja troca mútua de conhecimentos;

- fazer o levantamento das necessidades, interesses e habilidades do grupo de mães e professoras;

- selecionar sempre uma atividade para ser realizada e um tema para ser discutido na reunião subseqüente.

O contato com as mães, para a primeira reunião, foi por meio de convites elaborados pelas professoras e entregues pelos alunos e de visitas domiciliares feitas pelas professoras e por nós.

$\mathrm{Na}$ primeira reunião compareceram aproximadamente cinqüenta pessoas entre pais e professores. Embora o preparo e a elaboração desta reunião tenha sido feito por todo nosso grupo de mestrado, a coordenação foi realizada por nossa professora, uma vez que queríamos ter esta experiência de aprendizagem demonstrada por ela, para que pudéssemos, posteriormente, também coordenar. Pudemos, então, observar algumas técnicas de dinâmica de grupo e nos interessarmos por elas: utilização de comunicaçăo ñ̃-diretiva, formulação de perguntas abertas para facilitar a expressão verbal das mães e possibilitar a compreensão delas por nós.

Ao término da reunião fizemos, juntamente com as professoras da escolinha, nossa primeira avaliaçăo do ocorrido e programamos a reunião seguinte.

A cada encontro realizado na favela, nosso grupo, junto com nossa facilitadora, avaliávamos a reuniāo e planejávamos a seguinte. Cada reuniāo tinha um programa a ser desenvolvido; cada uma de nós dava sua colaboração e, juntas, decidíamos pelo programa.

$\grave{A}$ medida que se desenvolvia o trabalho com as mães surgia, cada vez mais, a necessidade de estudarmos vários aspectos de saúde pública, enfermagem pediátrica, comunicação e comunidade, entre outros. Muito tivemos que estudar a fim de nos sentirmos capacitadas para implementar este trabalho. 
O que foi mais valioso para nós foram as discussoes de grupo com a facilitadora, onde, além da análise do conteúdo das reuniões com as mães, colocávamos nossos sentimentos e emoções. desencadeados pelo trabalho na favela. Utilizávamos gravações em fitas dos nossos encontros para estudarmos nossa comunicação, pois sentíamos que a comunicação e o relacionamento no grupo eram importantes para conseguirmos atuar na comunidade.

Estávamos motivadas a levar à frente o trabalho; procurávamos bibliografia pertinente, procurávamos os recursos solicitados pelas mães, pesquisávamos e estudávamos os assuntos a serem discutidos com elas.

No começo, nosso trabalho na favela foi difícil. As nossas diferenças sócio-econômico-culturais dificultavam a comunicação. Tínhamos dúvidas quanto à determinaçâo do papel da enfermeira e quanto aos níveis de atuação naquela comunidade.

Pouco a pouco, as reuniões tornaram-se mais produtivas. Conseguimos perceber melhor os favelados: suas emoções, suas experiências, sua comunicação. suas expectativas e necessidades. Descobrimos que isto se processou a partir do momento em que conseguimos interagir com o comportamento do outro, apos vencermos uma primeira etapa de concentrarmos nossa atenção no nosso próprio comportamento.

Todas nós coordenamos reuniões com as mães. Sempre o fazíamos com o auxílio das outras colegas. Era a primeira vez. nesta metodologia, que trabalhávamos com uma comunidade e, portanto. o apoio da presença e interrençâo das colegas, quando necessário, fazia-se imprescindivel. Com as técnicas de dinâmica de grupo e a nâo-diretividade, além de nos atermos à fala. tentando essencialmente compreender a mensagem de quem falava, prestávamos também: atenção à comunicação nãoverbal. Conseguíamos. assim, interagir mais efetivamente com as mães, atendendo a suas necessidades, levando-ás à refiexào. à compreensão e à conscientização de suas ações, inclusive junto às suas crianças.

Em todos os assuntos escolhidos pelas mães e discutidos em nossos encontros. surpreendía-nos o grande arsenal de conhecimentos que as mães possuiam e nos desapontava o quanto elas nos ensinavam sem o saberem. Elas sabiam muito: um saber cultural e histórico. fundamentado nas raizes di seus antepassados e que tinha muito de cientifico: um saber em que acrea tavam e que, com exceção dos costumes supersticiosos. nos provavam os efeitos positivos de seus conhecimentos.

Conforme solicitaram as mães, conversamos sobre:

- como reconhecer diferentes doenças nas crianças - diarréia, desidratação. sarampo, verminose. desnutrição. febre;

- o que fazer com os acidentes domésticos mais comuns e como preveni-los: 
- como utilizar ervas naturais para tratar doenças;

- como é o dia-a-dia da mulher e da dinâmica familiar;

- como fazer pratos diferentes, entre eles, como preparar um bolo sem forno: e

- quais os cuidados com hipertensão e outras doenças.

Houve, também, a pedido das máes, alguns momentos de trabalhos manuais como tricô e crochê, como, também, a pedido delas, foi iniciada a alfabetização de adultos, pelo método de Paulo Freire, na qual partimos da palavra FA-VE-LA. (Esta alfabetização foi posteriormente continuada pelas professoras da Escolinha).

As reuniões se sucediam semanalmente. A cada nova reunião o clima de permissividade e de aceitação das mães, tais como elas realmente eram, sem críticas nem julgamentos aos que diziam, favorecia para que todas se comunicassem livremente, eram momentos de troca, de diálogo, de aprendizagem. Todas queriam falar, mas respeitavam a que falava, ouvindo-a.

Começamos a perceber mudanças na disposição das mães em freqüentarem os encontros. Percebemos que uma delas, por exemplo, inicialmente comparecia com uma touca a cobrir-lhe os cabelos e quase toda a fronte; posteriormente, cobria-lhe só os cabelos e, finalmente, ela comparecia com os cabelos presos e arrumados, mostrando todo o rosto.

Toda esta comunicaçâo não-verbal das mães, que denotava interesse ou gosto nas reunioes, incentivava-nos cada vez mais e fazia com que nós as respeitássemos e gostássemos delas cada vez mais.

A experiência na favela nos foi muito gratificante e ofereceu-nos inúmeras possibilidades de aprendizado. Reconhecemos que o trabalho desenvolvido junto, com a comunidade e não para a comunidade, é importante para ambos, favelados e profissionais da saúde, uma vez que estimula a criatividade do grupo como um todo, contribui para as mudanças desejadas com uma visão de ação conjunta, une os objetivos do profissional e da comunidade e, principalmente, valoriza o ser humano como capaz de identificar e solucionar seus problemas.

Havíamos conseguido vencer nosso desafio. As professoras e os voluntários haviam reconhecido e compreendido nosso trabalho com as mães e também o valorizavam; pretendiam continuar as reunioes e solicitaram os nomes dos livros que haviamos lido, para poderem trabalhar melhor.

A não continuidade de nosso trabalho na favela nos entristeceu, mas, além de aprender a trabalhar na comunidade, tínhamos outras necessidades de aprendizado igualmente significativas para nós. Além disso, tranquilizáva-nos o fato das professoras continuarem as reunioes com as mães; tínhamos 
decidido que a experiência que queríamos ter no seguinte semestre seria outra: a de divivenciar o papel de professor na metodologia de ensino centrado no estudante, com os alunos de graduação em enfermagem pediátrica, juntamente com as docentes daquela disciplina e com a participação da nossa professora como coordenadora do curso.

Só à medida que o curso foi-se desenvolvendo é que percebemos profundos processos de mudança em nós. Inicialmente, estávamos preocupadas em adquirir conhecimentos, obter informaçðes, receber bibliografia, a partir do momento em que tivemos oportunidade de expressar nosso desejos, sentimetos e necessidades, percebemos que obter conhecimentos e bibliografia não eram nossos desejos reais. Fizemos nossa primeira descoberta: ao expresarmos nossas necessidades, expressávamos a nós mesmas, integralmente; percebemos que, quando falávamos de nossa atividade profissional, expectativas e necessidades, falávamos de nós mesmas: como PENSÁVAMOS a respeito das coisas, como aquilo nos afetava e se incorporava sob forma de experiência vivida, que era única e infinitamente especial para nós individualmente; como SENTIAMOS aquelas experiências ou as necessidades que se tornavam claras para nós. Quantos sentimentos nos dominavam em cada pensamento ou ação!

Quantas coisas QUERÍAMOS realizar e quantas outras já tínhamos desejado, e todas, de maneira muito pessoal, que só nós, no nosso íntimo ser, sabíamos o que tinham representado ou o que representariam para nós.

Percebemos que éramos um ser integrado: em todo nosso ser sempre aparecia o PENSAR, o SENTIR e o QUERER AGIR.

Percebemos que o nosso eu pessoal, o nosso eu profissional e o nosso eu social eram um único, não poderíamos pensar com o "eu pessoal", agir com o "eu profissional" e sentir com o "eu social"; era impossível. Para sermos autênticas e felizes precisaríamos ser o "eu integral". Foi uma grande descoberta; descobrimos com isso o significado da pessoa "tornar-se um processo integrado de mudanças."

Neste momento, compreendernos a importância do objetivo acrescentado por nossa professora àquele formulado por nós. Ela havia acrescentado ao nosso:

- "Levar o estudante a se tornar um processo integrado de mudanças". Ao avaliarmos nosso trabalho na favela, concluímos que a nossa iniciativa fora um ato de coragem, pois acreditávamos que poderíamos trabalhar com um grupo e ousamos correr o risco. Sentimos uma necessidade: a de saber trabalhar em comunidade; encontramos uma solução: escolher uma comunidade para viver a experiência; decidimos a estratégia de aprendizado: gravação em fitas, reuniōes, a não diretividade e conseguimos construir a base, que redigimos como objetivo para nós, para sermos um bom professor, bom enfermeiro e bom pesquisador. 
A vivência nesta metodologia levou-nos a acreditar no seu efeito na pessoa dos alunos, considerando todo o processo que aconteceu em nós. 0 efeito desta metodologia dá-se em dois niveis: profissional e pessoal.

A auto-realização e auto-atualização são necessidades básicas do ser humano. A pessoa que é capaz de atendê-las vive mais efetivamente no seu mundo, ou seja:

- vë a realidade mais claramente;

- estabelece relações pessoas mais profundas;

- confia em si mesmo;

- é mais criativa;

- acha possível aprender com todas as pessoas;

- torna-se mais aberta para aceitar novas experiências, e

- adapta-se mais facilmente ao mundo de amanha.

Todas estas características podem ser agrupadas em duas categorias mais amplas: a de ser capaz de amar e ser amado e a de conseguir aprender e trabalhar mais efetivamente. A pessoa que consegue adquirir estas capacidades não precisa negar ou distorcer o que sente e o que é; ela se sente bem consigo mesma e com as outras pessoas. Nós acreditamos que esta é a meta do processo educativo e que o caminho para atingi-la é o ensino centrado no estudante.

NEIRA HUERTA, E. del P.; MADEIRA, L. M.; LAGANA, M. T. C.; MIRANDA, M. M. Student-centered teaching: an experience told by nursing studentes being taught un. der this method. Rev. Esc. Enf. USP, São Paulo, 18(2):141-149, 1984.

Four master's degree nursing students tell of their learning experience in a pediatric nursing program based on student-centered teaching methodology. The students relate their initial doubts about the effectivity of the methodology, the difficulties they encountered in formulating a program to be followed, and their observations of the behavior and the attitudes presented by their teacher-facilitator. In order to attain their particular learning objectives for the program, the group chose to start an experiment involving maternal-child care in a slum area of são Paulo. The students and their teacher worked with mothers and other adults responsible for child care, using nondirective communication. In this paper it's possible to identify the different necessary elements for a program. The authors believe that the main result of this experiment on them wor theer accomphisment as individuals and as professionals, as well as their own development as persons. 